\title{
The Fetal Origins of the Metabolic Syndrome: Can We Intervene?
}

\author{
Noelle $\mathrm{Ma}^{1,2,3}$ and Daniel B. Hardy ${ }^{1,2,3}$ \\ ${ }^{1}$ The Department of Physiology and Pharmacology, The University of Western Ontario, London, ON, Canada N6A 5C1 \\ ${ }^{2}$ The Department of Obstetrics \& Gynecology, The University of Western Ontario, London, ON, Canada N6A 5C1 \\ ${ }^{3}$ The Children's Health Research Institute, The Lawson Health Research Institute, London, ON, Canada N6A 4V2 \\ Correspondence should be addressed to Daniel B. Hardy, daniel.hardy@schulich.uwo.ca
}

Received 5 April 2012; Revised 23 July 2012; Accepted 8 August 2012

Academic Editor: Janna Morrison

Copyright ( $) 2012$ N. Ma and D. B. Hardy. This is an open access article distributed under the Creative Commons Attribution License, which permits unrestricted use, distribution, and reproduction in any medium, provided the original work is properly cited.

\begin{abstract}
Epidemiological studies have suggested that metabolic programming begins during fetal life and adverse events in utero are a critical factor in the etiology of chronic diseases and overall health. While the underlying molecular mechanisms linking impaired fetal development to these adult diseases are being elucidated, little is known about how we can intervene early in life to diminish the incidence and severity of these long-term diseases. This paper highlights the latest clinical and pharmaceutical studies addressing how dietary intervention in fetal and neonatal life may be able to prevent aspects of the metabolic syndrome associated with IUGR pregnancies.
\end{abstract}

\section{Introduction}

Clinical studies in humans have demonstrated that an adverse in utero environment (i.e., placental insufficiencyintrauterine growth restriction (IUGR)) contributes to longterm programming events leading to the metabolic syndrome, and ultimately, cardiovascular disease (CVD) [1-3]. This is of great interest considering that the incidence of IUGR (defined as birth weight below the 10th percentile) worldwide is estimated to be $15.5 \%$, and that number is greatly underestimated [4]. Moreover, the incidences of noncommunicable diseases such as heart disease, type II diabetes, hypertension, obesity are on the rise in North America [5-7], with more than one in three Americans exhibiting obesity [8]. Although the prevalence of these chronic and noncommunicable diseases puts tremendous strain on the health care system and society, intervention with diet or drugs may play a significant role to reduce their incidence. For example, a meta-analysis study, using data from 58 clinical trials as well as nine cohort studies, indicates that in patients with vascular disease, a $1.8 \mathrm{mM}$ reduction in LDL cholesterol by statins resulted in a $17 \%$ reduction in stroke and a $60 \%$ reduction in the risk of ischemic heart disease [9].

The problem is that current treatment for these diseases relies on the long-term use of pharmaceuticals in adults, which are not always efficacious for all individuals. For example, therapies using the statin class of lipid-lowering drugs to reduce hepatic cholesterol production have been successful in lowering LDL cholesterol by $24-61 \%$ [10]. However, while statin therapies are considered safe and effective in high doses, statins can lead to side effects including rhabdomyolysis, renal dysfunction, diabetes, and elevated liver enzymes [11]. This implies the need for additional strategies in disease prevention, not treatment.

Experiments of intrauterine growth restriction (IUGR) in animal models provide further evidence to support the hypothesis that impaired growth in utero via various maternal deficiencies leads to impairment of glucose, cholesterol, and triglyceride metabolism in adulthood [12-15]. In utero deficiencies that can lead to impaired growth in humans and animals include hypoxia [16], deficiencies in essential vitamins and minerals [17], diminished protein [15], caloric restriction [18], and excess glucocorticoids $[19,20]$. Although the correlation between impaired fetal growth and the risk for developing chronic disease in adulthood is undoubtedly strong, emerging human and animal studies are now investigating how we might be able to intervene in early life to reduce or prevent these longterm programming events. This paper aims to look at the current literature to highlight the possible pharmaceutical 
and dietary intervention strategies to reduce the incidence of the metabolic syndrome long-term in patients from complicated pregnancies (i.e. low birthweight).

\section{Ascorbic Acid (Vitamin C)}

The maintenance of adequate antioxidant systems in cells and tissues is essential to the defense system against free radicals and reactive oxygen species (ROS) [21]. When free radical generation overcomes the protective systems of the cell, it can lead to changes in DNA structure, enzyme activity, and distortion of cell structures [21,22]. Vitamins are a nonenzymatic and modifiable component of a cell's defense system. Vitamin C, a water-soluble vitamin, directly protects against aqueous peroxyl radicals, inhibiting initiated lipid peroxidation, and scavenges free radicals [23-25]. Vitamin E, a lipid-soluble vitamin, is able to prevent lipid peroxidation and can act as an inhibitor of free radical chain reactions [26]. Moreover, vitamins $\mathrm{C}$ and $\mathrm{E}$ have been shown to act synergistically, as vitamin $\mathrm{C}$ is able to help to regenerate and maintain levels of vitamin $\mathrm{E}$ [27].

Vitamins $\mathrm{C}$ and $\mathrm{E}$ have been investigated for use as an intervention method with the goal of preventing adverse pregnancy outcomes. Poor maternal environments including malnutrition and preeclampsia which have both been linked to IUGR, all have characteristically been shown to increase oxidative stress [28]. IUGR offspring have also been found to exhibit significantly lower expression of antioxidants [29]. Interestingly, in a prospective cohort study, after adjusting for factors such as vitamin supplementation, vitamins C and $\mathrm{E}$ have been positively correlated with birth weight and length [30]. Although, a direct causation between increased oxidative stress and adverse pregnancy outcomes has not been fully established, improving the defense systems of cells and tissues appears to be a logical first step in pregnancy intervention [29].

In a rodent model of diabetes-induced growth restriction, supplementations of vitamins $\mathrm{C}$ and $\mathrm{E}$ during pregnancy led to a decrease in markers of oxidative stress in offspring, but did not equally prevent fetal growth restriction [31]. Interestingly, in a rodent model of lipopolysaccharide (LPS) mediated IUGR, pre- or post LPS injection with vitamin $\mathrm{C}$ administration alleviated IUGR and attenuated lipid peroxidation. Pre-LPS treatment with vitamin C had a stronger effect by decreasing fetal death as well [32]. However, researchers noted that the timing of vitamin C administration was seemingly important, as vitamin C administration post-LPS injection decreased the effectiveness of a pre-LPS injection with vitamin C [32]. Vitamin C intervention appears to produce more promising outcomes when given prior to LPS-induced IUGR in rodent pregnancies.

Similarly, vitamin C has been pursued in human pregnancy trials. The majority of studies focused on a subpopulation of women at risk of preeclampsia; a maternal inflammatory response is believed to be mediated by a ROS imbalance $[33,34]$. It should be noted that IUGR is often a severe consequence associated with preeclampsia [35]. However, when vitamins $\mathrm{C}$ and $\mathrm{E}$ interventions were given to pregnant women, the results did not support the use of vitamins as a viable intervention in pregnancy. Researchers did not consistently find a difference in the risk of preeclampsia and did not observe a change in birth weight or risk of IUGR [33, 34, 36-38]. Interestingly, a decrease for the risk of developing preeclampsia and markers of oxidative stress was restricted to a population of high-risk pregnancies [39].

Finally, the safety of vitamin supplements during pregnancy remains questionable as two separate studies suggest intervention with vitamins leads to an increase in LBW and preterm births $[33,38]$. Thus, it still remains premature to determine the universal effectiveness of vitamin $\mathrm{C}$ or $\mathrm{E}$ supplementation during pregnancy for all populations of women.

\section{Folic Acid}

Folate, and its synthetic form, folic acid, acts as necessary cofactors for biochemical reactions, namely, the formation of S-adenosylmethionine, the main methyl donor for methylation. Folate plays an important role in cell growth and replication, as folate deficiency has been associated with inhibited cell growth, DNA repair, and the potentiation of oxidative stress leading to chromosomal abnormalities [40, 41]. The importance of folic acid during pregnancy was first discovered when it was found to substantially reduce the risk of developing neural tube defects if $400 \mu \mathrm{g}$ of folic acid was taken daily during the periconceptional period $[42,43]$.

Given its key role as a methyl donor, intervention with folic acid may initiate a possible epigenetic mechanism of early programming. In a rodent model of maternal protein restriction, hypomethylation of hepatic genes was observed, followed by a subsequent increase in gene expression levels. Folic acid supplemented to the restricted diet was able to prevent these epigenetic changes from occurring. It is conceivable that folic acid supplementation increases the availability of methyl groups for methylation [44]. Although providing additional methyl donors appears to prevent aberrant epigenetic changes, it is still important to determine whether additional methylation consistently translates into beneficial outcomes. For instance, Steegers-Theunissen et al. found that periconceptional intake of folic acid in mothers was directly related to an increase in methylation of the insulin growth-like factor 2 differentially methylated region (Igf2DM), which led to phenotypic consequences such as low birth weight [45].

Since folic acid during pregnancy has been incorporated into Western diet, research has expanded to determine whether there are additional benefits conferred to pregnant women and their offspring [46]. Using a retrospective database, one study observed that women exposed to folic acid antagonists were found to be at a greater risk for severe preeclampsia, fetal growth restriction, and even death [47]. Thus, the availability of folic acid during pregnancy appears to be critical in obtaining positive pregnancy outcomes. For example, an observational study of 832 women highlighted that folate intake of less than or equal to $240 \mu \mathrm{g}$ from diet and/or supplements during pregnancy, doubled 
the risk of bearing a child with LBW [48]. This relationship remained significant even after controlling for confounding variables such as low-energy intake and maternal age [48]. Furthermore, in a subpopulation of women from Crete, Greece, it was found that daily intake of $500 \mu \mathrm{g} /$ day of folic acid during early to midgestation presented another window of opportunity to lower the risk for preterm delivery, LBW $(<2500 \mathrm{~g})$ and IUGR births, all risk factors for early programming of adult onset diseases [49]. Interestingly, when folic acid supplementation was consumed before conception, it also decreased the risk of LBW and IUGR births [50].

In light of these arguments, it is still important to look at the long-term health outcomes of offspring exposed to maternal folic acid supplementation. The Pune Maternal Nutrition Study, a community-based prospective study, investigated a group of 1102 pregnant rural Indian women, of which the majority exhibited low vitamin B12 levels [51]. Yajnik et al. found that in offspring at six years of age from mothers who had low vitamin B12 levels during pregnancy and were concomitantly exposed to high levels of folate had children that were more insulin resistant [51]. The authors studied other imbalances and found that children born to mothers with higher folate levels were associated with greater adiposity and insulin resistance, while low maternal vitamin B12 levels during pregnancy were attributed to children who became insulin-resistant long-term. Their study elegantly highlight a surprising and possibly harmful role of folic acid intervention during gestation and the early programming of type 2 diabetes.

To date, controlled studies involving folic acid intervention have produced variable results. For example, a double-blind trial by Fletcher et al. demonstrated that there was no difference observed in birth weight, placental weight, or gestational duration between a folic acid and iron supplementation compared to an iron supplementation alone in a population of English women [52]. Similar findings demonstrating a lack of association between folic acid and LBW have also been established in a nonanemic subpopulation of pregnant women [53]. Therefore, care must be taken when drawing conclusions from controlled studies investigating links between folic acid supplementation and pregnancy outcomes because many studies involve different interventions, subpopulations, and methodology. Baumslag et al. most vividly demonstrated this phenomenon through an early study, where folic acid intervention was administered to two different subpopulations, consisting of Bantu and Caucasian pregnant women in South Africa [54]. The Bantu women exhibited a decrease of almost four times the risk of delivering a child less than $5 \mathrm{lbs}$ upon administration of $200 \mathrm{mg}$ of iron and $5 \mathrm{mg}$ of folic acid during pregnancy compared to an iron intervention alone. Interestingly, there were no benefits conferred to the Caucasian subpopulation on an average Western diet. The authors further suggest that folic acid supplementation would be most beneficial to target subpopulations with suboptimal diets [54].

Although much research must still be pursued before folic acid intervention is used in complicated pregnancies, understanding the molecular mechanisms of folic acid actions will help to characterize its promising and beneficial effects. Given the key roles that folic acid play in cell growth, it has been hypothesized to play a role in early programming of long-term modifications. Hypomethylation of genes involved in cardiovascular and metabolic control in the liver following weaning was observed in a rat model of maternal protein restriction. However, supplementation with folic acid prevented hypomethylation and subsequent expression of these genes. It is conceivable that folic acid supplementation did increase the availability of methyl groups available for methylation [44].

Having said that, it should be put into perspective that just because supplementation of folate in animal studies can improve a particular health-related outcome, it should not be concluded that supplementing folate will have an impact in the global prevalence of the problem. In addition, the toxicity of folic acid supplementation must also be considered before encouraging widespread use during pregnancy. High folate levels have been associated with decreases in nonspecific immunity and cancer promotion $[55,56]$.

\section{Multiple Micronutrients}

Maternal health and nutritional status have been considered one of the largest categories linked to perinatal morbidity [57]. Specifically, the level of micronutrients in the maternal diet can affect several pregnancy outcomes such as birth weight, gestational age at delivery, and perinatal mortality [58]. Often depending on the region, micronutrient deficiency may stem from an inadequate intake of animal source foods, an avoidance of milk or the influence of genetic polymorphisms that impair absorption or metabolism of nutrients [59]. Individual nutrient deficiencies have been explored including anemia development stemming from a lack of iron [60]. In addition, zinc deficiency is associated with preterm delivery and congenital abnormalities [60, 61].

There are several approaches that can be undertaken to improve maternal nutritional status, including an increase in foods that are high in micronutrient content or nutrient supplements, the latter of which are mainly employed in research [59]. However, micronutrient deficiencies often coexist, particularly in developing countries [62]. This feature has led to the development of multiple micronutrient (MMN) supplements in hopes of providing multiple benefits through a single intervention [62]. UNICEF, United Nations University, and the World Health Organization have produced supplements containing 15 micronutrients present at doses that are sufficient to meet the needs of pregnant women in developing countries [63].

Intervention studies using MMN supplementations have been pursued largely in developing countries and have produced mixed results. In Tanzania, 1075 HIV-1-infected pregnant women received daily MMN supplementation without vitamin A or vitamin A supplementation alone during gestation [64]. The multivitamin supplementation was able to decrease the risk of preterm births, LBW and IUGR at birth, while vitamin A alone did not affect these outcomes. Women who consumed multivitamins gave birth to heavier 
babies compared to those receiving vitamin A alone [64]. In Nepal, daily MMN supplementation led to an increase in body weight of offspring when compared to folic acid and iron supplementation alone. Multivitamin supplementation was associated with higher birth weight of offspring while gestational duration was unaffected [65]. This study targeted a mix of both rural and urban individuals likely representing a more common subgroup of the population. In a followup study in Nepal, children who were exposed to MMN prenatally were evaluated two to three years later. The weight gain observed at birth persisted into childhood [66]. In contrast, in a study carried out in Mexico, among a subgroup of relatively healthy women exposed to nearly daily MMN supplementation, the birth size of offspring was no larger compared to iron alone [67]. Although these results directly contradict previous studies, it is important to note that the formula of MMN supplementations differed slightly making direct comparisons complex. For example, in the Tanzanian study, the supplements included zinc, which was not present in the Mexican study.

In contrast to previous studies, Mathews et al. undertook a large-scale observational study on a population of pregnant women from an industrialized country, England [68]. Researchers observed no clinical effect of maternal nutrition on placental or birth weight at term. Moreover, vitamin $\mathrm{C}$ was the only nutrient that was found to have a positive correlation with placental and birth weight. However, researchers were skeptical that placental weight gain was clinically relevant. Together, these studies highlight the difference in efficacy of MMN supplementations and bring to light the importance of the population of women being studied.

Interestingly, researchers have begun focus on micronutrient rich foods and pregnancy outcomes. In a prospective study of 797 rural Indian women, Rao et al. demonstrated that birth size was related to intake of green leafy vegetables at 28 weeks of gestation and milk consumption at 18 weeks of gestation [69]. In the same way, a study on women in Burkina Faso observed beneficial effects such as an increase in birth length and an insignificant increase in birth weight of babies born to mothers who consumed fortified food supplement in addition to MMN supplements compared to consuming MMN supplements alone [70]. Yet, fortified food supplements were unable to prevent IUGR $(<10$ th percentile) or LBW $(<2500 \mathrm{~g})$ in offspring. Although causation was not established in either study, foodbased intervention should also be considered an attractive intervention method, providing another avenue and possibly more accessible methods to improve maternal nutritional status.

\section{Omega-3 Fatty Acids}

Omega-3 ( $\omega-3 / n-3)$ and omega-6 ( $\omega-6 / n-6)$ fatty acids can be obtained from the diet in their derivative forms, $\alpha$ linolenic acid (ALA) and linoleic acid (LA), respectively. These later become converted by the body into longer chain fatty acids including docosahexaenoic acid (DHA), eicosapentaenoic acid (EPA), and arachidonic acid (AA)
[71]. The conversion process is quite slow in humans, and it has since been discovered that EPA and DHA are present in fish oils and AA is present in the phospholipids of grain fed animals $[72,73]$. Fatty acids possess a critical structural role in cell membranes and are the parent compound for eicosanoid production [71]. Depending on the parent compound for eicosanoid production, omega-3 and -6 fatty acids play opposing physiological roles. Large amounts of eicosanoids production derived from omega-6derived LA leads to biologically active metabolic products and upon accumulation can contribute to the formation of thrombus and inflammatory disorders [71], while omega-3 fatty acids derived from fish oils have been shown to exhibit anti-inflammatory effects $[71,74]$. One of the first health benefits stemming from its consumption was observed in a study demonstrating an inverse relationship between fish consumption and the risk of coronary heart disease [75]. Subsequent studies treating hyperlipidemic patient populations with high doses of fish oil have also demonstrated the lipid lowering effects of omega-3 fatty acids [76]. The collective and pervasive actions of omega- 3 fatty acids may contribute to the prevention of coronary heart disease and hypertension [72].

Interestingly, omega-3 fatty acids have also been shown to be critical in fetal growth and essential for the development of the retina and brain [77]. Furthermore, in a community-based cohort study of healthy women, an association was found between low maternal concentrations of EPA and DHA and high concentrations of AA and a decrease in both fetal growth and birth weight of approximately 50 $60 \mathrm{~g}$ and increase risk of IUGR [78]. Researchers emphasized the importance of a balanced fatty acid profile in early pregnancy.

Controlled studies using omega-3 or fish fatty acids oil intervention during pregnancy have found moderately positive benefits. In a study of 533 healthy Danish women, daily consumption of fish oil tablets appeared to increase the length of gestation without impairment of parturition or growth [79]. Daily fish oil consumption from 20 weeks of gestation until delivery also appeared to decrease preterm delivery and extend the gestational period, in a European multicenter study of high-risk pregnancies [80]. Moreover, DHA supplementation during gestation in a large controlled trial significantly decreased the amount of births before 34 weeks of gestation, but increased the number of postterm births [81]. In an Indian population, with normally poor fish intake, an increase risk for LBW was observed in women who did not consume fish in their third trimester of pregnancy [82]. While Rogers et al. found a statistically significant decrease in the odds of IUGR reduction and omega-3 fatty acid consumption, no association was found between consumption and birth weight [83]. Surprisingly, the beneficial effects did not appear in a group of highrisk pregnancy cases as Onwude et al. found that DHA supplementation did not show a significant improvement in gestational length or birth weight [84].

Overall, fish oil supplementation during pregnancy appears to have moderate beneficial effects on pregnancy, especially on the length of gestation by two to three days 
which could potentially be a method for the prevention of preterm birth [85]. However, researchers warn that increasing gestational period may not be desirable if gestation is prolonged beyond term. The 2010 study by Makrides et al. indicated a decrease in preterm birth with omega-3 fatty acids, but a concomitant increase in the occurrence of postterm pregnancies [81]. Postterm pregnancies are also associated themselves with complications such as increased risk of stillbirth [86]. Secondly, studies have suggested that disproportionate high level of fish intake may decrease birth weight $[87,88]$. Collectively, these studies indicate that while omega-3 fatty acid supplementation appears to be a favourable intervention, the dosing of intervention must still be validated.

\section{Resveratrol}

Resveratrol, a polyphenol, is a protective molecule produced in response to stress by plants [89]. It is found in foods (i.e. grapes and berries), is readily absorbed and can be measured in human plasma [89-91]. It possesses several biological properties including antioxidant activities, vasorelaxant effects, and anticancer functions [92]. More importantly, postnatal resveratrol treatment has shown to prevent symptoms of the metabolic syndrome in hypoxiainduced IUGR from developing in adulthood [93].

Given the protective effects of postnatal resveratrol treatment, studies have been aimed at intervening at an earlier time point. Maternal resveratrol supplementation during gestation decreased fetal death by approximately $40 \%$ in a severe hypoxemia model in rats [94]. However, the surviving offspring that were growth restricted did not experience a change in fetal weight compared to control. Notably, resveratrol under normoxic conditions led to a decrease in placental weight also suggesting possible placental dysfunction [95]. Resveratrol intervention during pregnancy appears less effective in preventing the development of metabolic syndrome compared to postnatal intervention, but it conveys other protective properties to offspring.

Resveratrol has also been considered to help alleviate preeclampsia, and thus decreasing the risk of associated adverse outcomes. In vitro studies have demonstrated that resveratrol decreased the amount of soluble fmls-like tyrosine kinase (SFl-T) or vascular endothelial growth receptor-1 release from placental tissues, trophoblasts, and endothelial cells which are known to be elevated in preeclampsia [95]. Levels of SFl-T under a critical threshold are unable to elicit preeclampsia, thus highlighting a novel target of intervention [96].

In summary, resveratrol appears to be a safe therapeutic agent as no severe adverse outcomes were observed in human volunteers and demonstrated lack of teratogenicity in pregnant mice $[97,98]$.

\section{Melatonin}

Melatonin, N-acetyl-5-methoxytriptoamine, was first implicated in diurnal patterning and more recently found expressed at high levels in peripheral tissues [99]. Melatonin is considered an important antioxidant, capable of stimulating antioxidative enzymes, scavenging free radicals including superoxides, hydroxyl radicals, and hydrogen peroxide, and possessing repair capabilities [99-104]. Melatonin does not appear to adversely affect prenatal growth or viability in offspring following short-term exposure after pregnancy has been established [99]. With its widespread antioxidant abilities and lack of apparent toxicity, melatonin appears to be an ideal candidate for intervention use in adverse pregnancies.

Richter et al. investigated whether the protective effects of melatonin could improve placental antioxidant capacity in rat pregnancies complicated by undernutrition [105]. Melatonin administration during gestation demonstrated restored body weight of offspring at birth and an increase in some antioxidative enzymes, including manganese superoxide dismutase and catalase [105]. In an ovine model, melatonin promoted vasodilation of umbilical blood flow, which may be a mechanism by which fetal growth could be rescued during a complicated pregnancy [106]. In a second ovine model of under nutrition-induced IUGR, short-term exposure to melatonin during gestation was similarly able to increase umbilical cord blood flow [107]. However, melatonin intervention did not rescue fetal weight in nutrientrestricted ewes. The timing of melatonin administration was also investigated in a rodent model of LPS-induced IUGR [108]. In this study, melatonin was administered either postLPS injection alone or before and post-LPS injection. It was found that posttreatment with melatonin alone led to a decrease in intrauterine fetal death (IUFD) in a dosedependent manner while administration of both pre- and postinjections almost completely ablated the risk of IUFD and reversed LPS-induced skeletal development retardation. Although the benefits of melatonin were unquestionable, there was still minimal effect observed on recovering fetal weight [109].

\section{Exendin-4}

Exendin-4 (Ex-4) is a 39 amino acid peptide and shares $53 \%$ homology with glucagon-like peptide 1 (GLP-1) [108]. GLP1 stimulates insulin secretion and inhibits glucagon secretion and gastric emptying [110]. GLP-1 has also been found to be essential for normalizing fasting glucose levels in diabetic patients $[111,112]$. However, GLP-1 agonists themselves are inefficient at maintaining long-term activation, and other analogues have been since investigated have been more resistant to degradation $[113,114]$. Ex-4, an analog of GLP1 , has been shown to exert antidiabetic functions such as decreasing plasma glucose concentration, food intake, body weight, and fasting triglyceride levels [114]. Moreover, Ex-4 is able to elicit an approximately ten-fold greater maximal insulinotropic effect compared to GLP-1 $[115,116]$. Ex-4 also binds to endogenous GLP-1 receptor (GLP-1R) expressed in $\beta$-cells and is a more potent agonist compared to GLP-1 $[115,117]$.

The astounding effects of Ex-4 were observed following an increase in pancreatic neogenesis and differentiation of $\beta$-cells in rats after a partial pancreatectomy [118]. Clearly, 
Ex-4 is an extremely appealing therapeutic agent for the treatment of diabetes. Ex- 4 has been used to treat type II diabetes patients that were previously unable to reach normal glycemic control even when using maximal dosages of metformin [119]. Exenatide, a synthetic form of Ex-4, was able to improve glycemic control, proinsulin to insulin ratio, without any of the risks of other antidiabetic drugs [119]. Furthermore, it was shown that exenatide led to a prompt reduction in both fasting and postprandial glucose levels in diabetic patients [120]. The insulinotropic effects and suppression of glucagon observed appeared to be glucosedependent, negating the risk of hypoglycemia and improving the safety of exenatide use [120]. Interestingly, IUGR rat offspring have been shown to be at risk of developing type II diabetes in adulthood and have a decreased amount of $\beta$ cells long-term [121]. The use of Ex-4 could theoretically ameliorate glucose regulation and decrease the risk of developing type II diabetes in these offspring.

Using rodent models, short-term administration of Ex4 immediately following birth demonstrated normalization of glucose tolerance and rescue of eventual $\beta$-cell mass decline [122]. These findings were encouraging, and the mechanisms underlying the prevention of diabetes in an IUGR rat model have been investigated. Ex- 4 was able to normalize Pancreatic and duodenal homeobox 1 ( $\mathrm{Pdx}-1)$ transcription, which is a transcription factor necessary for $\beta$-cell function and development, while also permanently reversing an aberrant Pdx-1 chromatin environment [123]. It has also been shown that Ex-4 is able to regulate the vascular environment surrounding $\beta$-cells. The vascular environment plays an important role in normal pancreatic function through its ability to produce signals for differentiation and development, and the delivery of nutrients to $\beta$-cells. IUGR offspring have decreased islet vascular density, weeks before a loss of $\beta$-cell mass [124]. Researchers suggested that the vascularity of the pancreas is extremely important in determining the amount of $\beta$-cells present in offspring. Following short-term neonatal exposure to Ex-4 in IUGR rats, islet vascularity was promptly restored to control levels [124]. It is clear that Ex-4 and exenatide as therapeutic agents should be further explored in the prevention of developing diabetes from an adverse in utero environment.

\section{Nuclear Receptor Agonists}

Nuclear receptors represent the largest family of transcription factors found in metazoans, binding to steroid hormones, fat-soluble vitamins, along with oxysterols and bile acids from the diet. Although the roles of many nuclear receptors are well defined in adults, very little is known about their role in fetal development and long-term disease. The use of nuclear receptor agonists as therapeutic intervention in animal models of IUGR is a novel approach that is only just being explored. The peroxisome proliferatoractivated receptor gamma (PPAR $\gamma)$, another lipid-sensing nuclear receptor, has been investigated as a target for intervention in neonatal life. PPAR $y$ is a key target of insulin-sensitizing drugs thiazolidinediones and is involved in adipocyte differentiation [125]. PPAR $y$ agonist-treated
IUGR female offspring showed insulin-sensitizing effects; however, offspring exhibited severe hypoglycemia as well [126].

Our recent studies have demonstrated that in maternal protein restriction (MPR) in rats during pregnancy and lactation, the offspring are low birth weight offspring, with permanent elevation in circulating cholesterol and impaired glucose homeostasis $[15,127]$. Moreover, these MPR offspring were characterized by a diminished expression of the nuclear receptor, $\operatorname{LXR} \alpha$, and therefore, deregulated expression of LXR $\alpha$-target genes [15, 127]. Given the regulatory role of LXR in cholesterol, triglyceride, and glucose homeostasis [128-131], it is conceivable for the use LXR agonists in vivo to improve the expression of LXR target genes and rescue the offspring from undernutrition. In hopes of ameliorating LXR target genes, LXR agonists (GW3695) were administered from postnatal day 5 to 15 . Interestingly, by three weeks of age posttreated, LXR agonist-treated offspring had decreased circulating cholesterol: HDL ratios, concomitant with increased LXR $\alpha$ and Cyp7al expression, and the critical LXR-target enzyme involved in cholesterol catabolism [132]. Furthermore, this was also associated with a more permissive chromatin environment at the promoter region of Cyp7a1 [132]. These results suggest that maternal protein restriction insults in utero are reversible and future studies will focus on the effects of neonatal LXR agonist intervention in adulthood along with the possibility that glucose impairment could be reversed as well. To date, our preliminary data highlights the promising role of nuclear receptors as therapeutic agents in reversing early programming of long-term disease.

\section{Conclusion}

As we elucidate the molecular mechanisms underlying the early programming of adult disease, we come closer to not only understanding the development of these diseases but in preventing their onset as well. This paper highlighted some of the current nutritional and pharmacological approaches to date, indicating their short- and long-term beneficial and detrimental effects. Most likely, the most promising targets for the investigation of early programming in the near future will be compounds, which will target common transcription factors (e.g., nuclear receptors) involved in multiple pathways. For example, given that $\operatorname{LXR} \alpha$ plays a major role in cholesterol, lipid, and glucose homeostasis, it becomes an attractive auspicious candidate for therapeutic targets. In the meantime, known dietary supplements appear promising, even while the dose and frequencies of intervention are still under great investigation. The onus for us remains to further understand the window of opportunity in perinatal life for intervention, which can vary depending on the pregnancyassociated insult.

\section{Acknowledgment}

This work is supported by CIHR Operating Grant and Natural Sciences and Engineering Research Council of Canada. 


\section{References}

[1] D. J. P. Barker, C. N. Hales, C. H. D. Fall, C. Osmond, K. Phipps, and P. M. S. Clark, "Type 2 (non-insulin-dependent) diabetes mellitus, hypertension and hyperlipidaemia (syndrome X): relation to reduced fetal growth," Diabetologia, vol. 36, no. 1, pp. 62-67, 1993.

[2] D. Jaquet, A. Gaboriau, P. Czernichow, and C. Levy-Marchal, "Insulin resistance early in adulthood in subjects born with intrauterine growth retardation," The Journal of Clinical Endocrinology and Metabolism, vol. 85, no. 4, pp. 1401-1406, 2000.

[3] P. M. Nilsson, P. O. Östergren, P. Nyberg, M. Söderström, and P. Allebeck, "Low birth weight is associated with elevated systolic blood pressure in adolescence: a prospective study of a birth cohort of 149,378 Swedish boys," Journal of Hypertension, vol. 15, no. 12, pp. 1627-1631, 1997.

[4] A. D. Lopez, C. D. Mathers, M. Ezzati, D. T. Jamison, and C. J. Murray, "Global and regional burden of disease and risk factors, 2001: systematic analysis of population health data," The Lancet, vol. 367, no. 9524, pp. 1747-1757, 2006.

[5] E. S. Ford, W. H. Giles, and A. H. Mokdad, "Increasing prevalence of the metabolic syndrome among U.S. adults," Diabetes Care, vol. 27, no. 10, pp. 2444-2449, 2004.

[6] D. Lloyd-Jones, R. J. Adams, T. M. Brown et al., "Executive summary: heart disease and stroke statistics-2010 update: a report from the american heart association," Circulation, vol. 121, no. 7, pp. e46-e215, 2010.

[7] S. McGuire, "Shields M., Carroll M.D., Ogden C.L. adult obesity prevalence in Canada and the United States. NCHS data brief no. 56, Hyattsville, MD: national Center for Health Statistics, 2011," Advances in Nutrition, vol. 2, no. 4, pp. 368$369,2011$.

[8] C. L. Ogden, M. D. Carroll, B. K. Kit, and K. M. Flegal, "Prevalence of obesity and trends in body mass index among US children and adolescents, 1999-2010," JAMA, vol. 307, no. 5, pp. 483-490, 2012.

[9] M. R. Law, N. J. Wald, and A. R. Rudnicka, "Quantifying effect of statins on low density lipoprotein cholesterol, ischaemic heart disease, and stroke: systematic review and meta-analysis," BMJ, vol. 326, no. 7404, pp. 1423-1427, 2003.

[10] J. C. LaRosa, J. He, and S. Vupputuri, "Effect of statins on risk of coronary disease. A meta-analysis of randomized controlled trials," JAMA, vol. 282, no. 24, pp. 2340-2346, 1999.

[11] C. Escobar, R. Echarri, and V. Barrios, "Relative safety profiles of high dose statin regimens," Vascular Health and Risk Management, vol. 4, no. 3, pp. 525-533, 2008.

[12] S. C. Langley, R. F. Browne, and A. A. Jackson, "Altered glucose tolerance in rats exposed to maternal low protein diets in utero," Comparative Biochemistry and Physiology-A Physiology, vol. 109, no. 2, pp. 223-229, 1994.

[13] S. Dahri, A. Snoeck, B. Reusens-Billen, C. Remacle, and J. J. Hoet, "Islet function in offspring of mothers on low-protein diet during gestation," Diabetes, vol. 40, no. 2, pp. 115-120, 1991.

[14] A. Lucas, B. A. Baker, M. Desai, and C. N. Hales, "Nutrition in pregnant or lactating rats programs lipid metabolism in the offspring," British Journal of Nutrition, vol. 76, no. 4, pp. 605-612, 1996.

[15] G. Sohi, K. Marchand, A. Revesz, E. Arany, and D. B. Hardy, "Maternal protein restriction elevates cholesterol in adult rat offspring due to repressive changes in histone modifications at the cholesterol $7 \alpha$-hydroxylase promoter," Molecular Endocrinology, vol. 25, no. 5, pp. 785-798, 2011.

[16] Z. Wang, Z. Huang, G. Lu, L. Lin, and M. Ferrari, "Hypoxia during pregnancy in rats leads to early morphological changes of atherosclerosis in adult offspring," American Journal of Physiology, vol. 296, no. 5, pp. H1321-H1328, 2009.

[17] R. M. Lewis, L. A. James, J. Zhang, C. D. Byrne, and C. N. Hales, "Effects of maternal iron restriction in the rat on hypoxia-induced gene expression and fetal metabolite levels," British Journal of Nutrition, vol. 85, no. 2, pp. 193-201, 2001.

[18] S. M. Woodall, B. M. Johnston, B. H. Breier, and P. D. Gluckman, "Chronic maternal undernutrition in the rat leads to delayed postnatal growth and elevated blood pressure of offspring," Pediatric Research, vol. 40, no. 3, pp. 438-443, 1996.

[19] R. Benediktsson, R. S. Lindsay, J. Noble, J. R. Seckl, and C. R. W. Edwards, "Glucocorticoid exposure in utero: new model for adult hypertension," The Lancet, vol. 341, no. 8841, pp. 339-341, 1993.

[20] R. M. Reynolds, "Corticosteroid-mediated programming and the pathogenesis of obesity and diabetes," Journal of Steroid Biochemistry and Molecular Biology, vol. 122, no. 13, pp. 3-9, 2010.

[21] L. J. Machlin and A. Bendich, "Free radical tissue damage: protective role of antioxidant nutrients," The FASEB Journal, vol. 1, no. 6, pp. 441-445, 1987.

[22] T. F. Slater, "Free-radical mechanisms in tissue injury," Biochemical Journal, vol. 222, no. 1, pp. 1-15, 1984.

[23] R. S. Bodannes and P. C. Chan, "Ascorbic acid as a scavenger of singlet oxygen,” FEBS Letters, vol. 105, no. 2, pp. 195-196, 1979.

[24] B. Frei, L. England, and B. N. Ames, "Ascorbate is an outstanding antioxidant in human blood plasma," Proceedings of the National Academy of Sciences of the United States of America, vol. 86, no. 16, pp. 6377-6381, 1989.

[25] M. Nishikimi, "Oxidation of ascorbic acid with superoxide anion generated by the xanthine xanthine oxidase system," Biochemical and Biophysical Research Communications, vol. 63, no. 2, pp. 463-468, 1975.

[26] P. B. McCay, "Vitamin E: interactions with free radicals and ascorbate," Annual Review of Nutrition, vol. 5, pp. 323-340, 1985.

[27] J. E. Packer, T. F. Slater, and R. L. Willson, "Direct observation of a free radical interaction between vitamin $\mathrm{E}$ and vitamin C," Nature, vol. 278, no. 5706, pp. 737-738, 1979.

[28] H. W. Yung, S. Calabrese, D. Hynx et al., "Evidence of placental translation inhibition and endoplasmic reticulum stress in the etiology of human intrauterine growth restriction," American Journal of Pathology, vol. 173, no. 2, pp. 451-462, 2008.

[29] P. Gupta, M. Narang, B. D. Banerjee, and S. Basu, "Oxidative stress in term small for gestational age neonates born to undernourished mothers: a case control study," BMC Pediatrics, vol. 4, article 14, 2004.

[30] B. E. Lee, Y. C. Hong, K. H. Lee et al., "Influence of maternal serum levels of vitamins $\mathrm{C}$ and $\mathrm{E}$ during the second trimester on birth weight and length," European Journal of Clinical Nutrition, vol. 58, no. 10, pp. 1365-1371, 2004.

[31] A. Ornoy, M. Avgil Tsadok, P. Yaffe, and S. W. Zangen, “The Cohen diabetic rat as a model for fetal growth restriction: vitamins $\mathrm{C}$ and $\mathrm{E}$ reduce fetal oxidative stress but do not 
restore normal growth," Reproductive Toxicology, vol. 28, no. 4, pp. 521-529, 2009.

[32] Y. H. Chen, D. X. Xu, L. Zhao, H. Wang, J. P. Wang, and W. Wei, "Ascorbic acid protects against lipopolysaccharideinduced intra-uterine fetal death and intra-uterine growth retardation in mice," Toxicology, vol. 217, no. 1, pp. 39-45, 2006.

[33] L. Poston, A. Briley, P. Seed, F. Kelly, and A. Shennan, "Vitamin C and vitamin E in pregnant women at risk for preeclampsia (VIP trial): randomised placebo-controlled trial," The Lancet, vol. 367, no. 9517, pp. 1145-1154, 2006.

[34] A. R. Rumbold, C. A. Crowther, R. R. Haslam, G. A. Dekker, and J. S. Robinson, "Vitamins $\mathrm{C}$ and $\mathrm{E}$ and the risks of preeclampsia and perinatal complications," The New England Journal of Medicine, vol. 354, no. 17, pp. 1796-1806, 2006.

[35] S. K. Srinivas, A. G. Edlow, P. M. Neff, M. D. Sammel, C. M. Andrela, and M. A. Elovitz, "Rethinking IUGR in preeclampsia: dependent or independent of maternal hypertension?" Journal of Perinatology, vol. 29, no. 10, pp. 680-684, 2009.

[36] A. Conde-Agudelo, R. Romero, J. P. Kusanovic, and S. S. Hassan, "Supplementation with vitamins $\mathrm{C}$ and e during pregnancy for the prevention of preeclampsia and other adverse maternal and perinatal outcomes: a systematic review and metaanalysis," American Journal of Obstetrics and Gynecology, vol. 204, no. 6, pp. 503.e1-503.e12, 2011.

[37] D. Beazley, R. Ahokas, J. Livingston, M. Griggs, and B. M. Sibai, "Vitamin C and E supplementation in women at high risk for preeclampsia: a double-blind, placebo-controlled trial," American Journal of Obstetrics and Gynecology, vol. 192, no. 2, pp. 520-521, 2005.

[38] A. Rumbold and C. A. Crowther, "Vitamin C supplementation in pregnancy," Cochrane Database of Systematic Rreviews, no. 2, Article ID CD004072, 2005.

[39] L. C. Chappell, P. T. Seed, A. L. Briley et al., "Effect of antioxidants on the occurrence of pre-eclampsia in women at increased risk: a randomised trial," The Lancet, vol. 354, no. 9181, pp. 810-816, 1999.

[40] S. J. Duthie and A. Hawdon, "DNA instability (strand breakage, uracil misincorporation, and defective repair) is increased by folic acid depletion in human lymphocytes in vitro," The FASEB Journal, vol. 12, no. 14, pp. 1491-1497, 1998.

[41] M. L. Cravo, J. B. Mason, Y. Dayal et al., "Folate deficiency enhances the development of colonic neoplasia in dimethylhydrazine-treated rats," Cancer Research, vol. 52, no. 18, pp. 5002-5006, 1992.

[42] R. J. Berry, Z. Li, J. D. Erickson et al., "Prevention of neuraltube defects with folic acid in China," The New England Journal of Medicine, vol. 341, no. 20, pp. 1485-1490, 1999.

[43] A. Milunsky, H. Jick, S. S. Jick et al., "Multivitamin/folic acid supplementation in early pregnancy reduces the prevalence of neural tube defects," JAMA, vol. 262, no. 20, pp. 28472852, 1989.

[44] K. A. Lillycrop, E. S. Phillips, A. A. Jackson, M. A. Hanson, and G. C. Burdge, "Dietary protein restriction of pregnant rats induces and folic acid supplementation prevents epigenetic modification of hepatic gene expression in the offspring," Journal of Nutrition, vol. 135, no. 6, pp. 13821386, 2005.

[45] R. P. Steegers-Theunissen, S. A. Obermann-Borst, D. Kremer et al., "Periconceptional maternal folic acid use of $400 \mu \mathrm{g}$ per day is related to increased methylation of the IGF2 gene in the very young child," PLoS ONE, vol. 4, no. 11, Article ID e7845, 2009.

[46] M. A. Honein, L. J. Paulozzi, T. J. Mathews, J. D. Erickson, and L. Y. C. Wong, "Impact of folic acid fortification of the US food supply on the occurrence of neural tube defects," JAMA, vol. 285, no. 23, pp. 2981-2986, 2001.

[47] S. W. Wen, J. Zhou, Q. Yang, W. Fraser, O. Olatunbosun, and M. Walker, "Maternal exposure to folic acid antagonists and placenta-mediated adverse pregnancy outcomes," CMAJ, vol. 179, no. 12, pp. 1263-1268, 2008.

[48] T. O. Scholl, M. L. Hediger, J. I. Schall, C.-S. Khoo, and R. L. Fischer, "Dietary and serum folate: their influence on the outcome of pregnancy," American Journal of Clinical Nutrition, vol. 63, no. 4, pp. 520-525, 1996.

[49] E. Papadopoulou, N. Stratakis, T. Roumeliotaki et al., "The effect of high doses of folic acid and iron supplementation in early-to-mid pregnancy on prematurity and fetal growth retardation: the mother-child cohort study in Crete, Greece (Rhea study)," European Journal of Nutrition. In press.

[50] S. Timmermans, V. W. V. Jaddoe, A. Hofman, R. P. M. Steegers-Theunissen, and E. A. P. Steegers, "Periconception folic acid supplementation, fetal growth and the risks of low birth weight and preterm birth: the Generation R Study," British Journal of Nutrition, vol. 102, no. 5, pp. 777-785, 2009.

[51] C. S. Yajnik, S. S. Deshpande, A. A. Jackson et al., "Vitamin B12 and folate concentrations during pregnancy and insulin resistance in the offspring: the Pune Maternal Nutrition Study," Diabetologia, vol. 51, no. 1, pp. 29-38, 2008.

[52] J. Fletcher, A. Gurr, F. R. Fellingham, T. A. J. Prankerd, H. A. Brant, and D. N. Menzies, "The value of folic acid supplements in pregnancy," Journal of Obstetrics and Gynaecology of the British Commonwealth, vol. 78, no. 9, pp. 781-785, 1971.

[53] S. Palma, R. Perez-Iglesias, D. Prieto, R. Pardo, J. Llorca, and M. Delgado-Rodriguez, "Iron but not folic acid supplementation reduces the risk of low birthweight in pregnant women without anaemia: a case-control study," Journal of Epidemiology and Community Health, vol. 62, no. 2, pp. 120124, 2008.

[54] N. Baumslag, T. Edelstein, and J. Metz, "Reduction of incidence of prematurity by folic acid supplementation in pregnancy," BMJ, vol. 1, no. 687, pp. 16-17, 1970.

[55] A. M. Troen, B. Mitchell, B. Sorensen et al., "Unmetabolized folic acid in plasma is associated with reduced natural killer cell cytotoxicity among postmenopausal women," Journal of Nutrition, vol. 136, no. 1, pp. 189-194, 2006.

[56] Y. I. Kim, "Will mandatory folic acid fortification prevent or promote cancer?" American Journal of Clinical Nutrition, vol. 80, no. 5, pp. 1123-1128, 2004.

[57] M. A. Koblinsky, "Beyond maternal mortality-magnitude, interrelationship, and consequences of women's health, pregnancy-related complications and nutritional status on pregnancy outcomes," International Journal of Gynecology and Obstetrics, vol. 48, supplement, pp. S21-S32, 1995.

[58] U. Ramakrishnan, R. Manjrekar, J. Rivera, T. GonzálesCossío, and R. Martorell, "Micronutrients and pregnancy outcome: a review of the literature," Nutrition Research, vol. 19, no. 1, pp. 103-159, 1999.

[59] L. H. Allen, "Multiple micronutrients in pregnancy and lactation: an overview," American Journal of Clinical Nutrition, vol. 81, no. 5, pp. 1206S-1212S, 2005.

[60] J. L. Beard, "Effectiveness and strategies of iron supplementation during pregnancy," American Journal of Clinical Nutrition, vol. 71, no. 5, pp. 1288S-1294S, 2000. 
[61] S. Jameson, "Zinc status in pregnancy: the effect of zinc therapy on perinatal mortality, prematurity and placental ablation," Annals of the New York Academy of Sciences, vol. 678, pp. 178-192, 1993.

[62] R. E. Black, "Micronutrients in pregnancy," British Journal of Nutrition, vol. 85, supplement 2, pp. S193-S197, 2001.

[63] Composition of a Multi-Micronutrient Supplement to Be Used in Pilot programmes among pregnant Women in Developing Countries, UNICEF/WHO, New York, NY, USA, 1999.

[64] W. W. Fawzi, G. I. Msamanga, D. Spiegelman et al., "Randomised trial of effects of vitamin supplements on pregnancy outcomes and T cell counts in HIV-1-infected women in Tanzania," The Lancet, vol. 351, no. 9114, pp. 1477-1482, 1998.

[65] D. Osrin, A. Vaidya, Y. Shrestha et al., "Effects of antenatal multiple micronutrient supplementation on birthweight and gestational duration in Nepal: double-blind, randomised controlled trial," The Lancet, vol. 365, no. 9463, pp. 955-962, 2005.

[66] A. Vaidya, N. Saville, B. P. Shrestha, A. M. de L Costello, D. S. Manandhar, and D. Osrin, "Effects of antenatal multiple micronutrient supplementation on children's weight and size at 2 years of age in Nepal: follow-up of a double-blind randomised controlled trial," The Lancet, vol. 371, no. 9611, pp. 492-499, 2008.

[67] U. Ramakrishnan, T. González-Cossío, L. M. Neufeld, J. Rivera, and R. Martorell, "Multiple micronutrient supplementation during pregnancy does not lead to greater infant birth size than does iron-only supplementation: a randomized controlled trial in a semirural community in Mexico," American Journal of Clinical Nutrition, vol. 77, no. 3, pp. 720-725, 2003.

[68] F. Mathews, P. Yudkin, and A. Neil, "Influence of maternal nutrition on outcome of pregnancy: prospective cohort study," BMJ, vol. 319, no. 7206, pp. 339-343, 1999.

[69] S. Rao, C. S. Yajnik, A. Kanade et al., "Intake of micronutrient-rich foods in rural Indian mothers is associated with the size of their babies at birth: pune maternal nutrition study," Journal of Nutrition, vol. 131, no. 4, pp. 1217-1224, 2001.

[70] L. Huybregts, D. Roberfroid, H. Lanou et al., "Prenatal food supplementation fortified with multiple micronutrients increases birth length: a randomized controlled trial in rural Burkina Faso," American Journal of Clinical Nutrition, vol. 90, no. 6, pp. 1593-1600, 2009.

[71] A. P. Simopoulos, "Importance of the ratio of omega6/omega-3 essential fatty acids: evolutionary aspects," World Review of Nutrition and Dietetics, vol. 92, pp. 1-22, 2003.

[72] A. P. Simopoulos, "Omega-3 fatty acids in health and disease and in growth and development," American Journal of Clinical Nutrition, vol. 54, no. 3, pp. 438-463, 1991.

[73] L. M. Arterburn, E. B. Hall, and H. Oken, "Distribution, interconversion, and dose response of n-3 fatty acids in humans," American Journal of Clinical Nutrition, vol. 83, no. 6, pp. 1467S-1476S, 2006.

[74] S. Endres, R. Ghorbani, V. E. Kelley et al., "The effect of dietary supplementation with n-3 polyunsaturated fatty acids on the synthesis of interleukin-1 and tumor necrosis factor by mononuclear cells," The New England Journal of Medicine, vol. 320, no. 5, pp. 265-271, 1989.

[75] D. Kromhout, E. B. Bosschieter, and C. De Lezenne Coulander, "The inverse relation between fish consumption and 20 -year mortality from coronary heart disease," The New
England Journal of Medicine, vol. 312, no. 19, pp. 1205-1209, 1985.

[76] B. E. Phillipson, D. W. Rothrock, and W. E. Connor, "Reduction of plasma lipids, lipoproteins, and apoproteins by dietary fish oils in patients with hypertriglyceridemia," The New England Journal of Medicine, vol. 312, no. 19, pp. 1210-1216, 1985.

[77] M. Neuringer, W. E. Connor, and D. S. Lin, "Biochemical and functional effects of prenatal and postnatal $\omega 3$ fatty acid deficiency on retina and brain in rhesus monkeys," Proceedings of the National Academy of Sciences of the United States of America, vol. 83, no. 11, pp. 4021-4025, 1986.

[78] M. Van Eijsden, G. Hornstra, M. F. Van Der Wal, T. G. M. Vrijkotte, and G. J. Bonsel, "Maternal n-3, n-6, and trans fatty acid profile early in pregnancy and term birth weight: a prospective cohort study," American Journal of Clinical Nutrition, vol. 87, no. 4, pp. 887-895, 2008.

[79] S. F. Olsen, J. D. Sorensen, N. J. Secher et al., "Randomised controlled trial of effect of fish-oil supplementation on pregnancy duration," The Lancet, vol. 339, no. 8800, pp. 1003-1007, 1992.

[80] S. F. Olsen, N. J. Secher, A. Tabor, T. Weber, J. J. Walker, and C. Gluud, "Randomised clinical trials of fish oil supplementation in high risk pregnancies," BJOG, vol. 107, no. 3, pp. 382-395, 2000.

[81] M. Makrides, R. A. Gibson, A. J. McPhee et al., "Effect of DHA supplementation during pregnancy on maternal depression and neurodevelopment of young children: a randomized controlled trial," JAMA, vol. 304, no. 15, pp. 1675-1683, 2010.

[82] S. Muthayya, P. Dwarkanath, T. Thomas et al., "The effect of fish and $\omega$-3 LCPUFA intake on low birth weight in Indian pregnant women," European Journal of Clinical Nutrition, vol. 63, no. 3, pp. 340-346, 2009.

[83] I. Rogers, P. Emmett, A. Ness, and J. Golding, "Maternal fish intake in late pregnancy and the frequency of low birth weight and intrauterine growth retardation in a cohort of British infants," Journal of Epidemiology and Community Health, vol. 58, no. 6, pp. 486-492, 2004.

[84] J. L. Onwude, R. J. Lilford, H. Hjartadottir, A. Staines, and D. Tuffnell, "A randomised double blind placebo controlled trial of fish oil in high risk pregnancy," British Journal of Obstetrics and Gynaecology, vol. 102, no. 2, pp. 95-100, 1995.

[85] M. Makrides, L. Duley, and S. F. Olsen, "Marine oil, and other prostaglandin precursor, supplementation for pregnancy uncomplicated by pre-eclampsia or intrauterine growth restriction," Cochrane Database of Systematic Reviews, vol. 3, Article ID CD003402, 2006.

[86] L. Hilder, K. Costeloe, and B. Thilaganathan, "Prolonged pregnancy: evaluating gestation-specific risks of fetal and infant mortality," British Journal of Obstetrics and Gynaecology, vol. 105, no. 2, pp. 169-173, 1998.

[87] P. Grandjean, K. S. Bjerve, P. Weihe, and U. Steuerwald, "Birthweight in a fishing community: significance of essential fatty acids and marine food contaminants," International Journal of Epidemiology, vol. 30, no. 6, pp. 1272-1278, 2001.

[88] E. Oken, K. P. Kleinman, S. F. Olsen, J. W. Rich-Edwards, and M. W. Gillman, "Associations of seafood and elongated n-3 fatty acid intake with fetal growth and length of gestation: results from a US pregnancy cohort," American Journal of Epidemiology, vol. 160, no. 8, pp. 774-783, 2004.

[89] P. Signorelli and R. Ghidoni, "Resveratrol as an anticancer nutrient: molecular basis, open questions and promises," 
Journal of Nutritional Biochemistry, vol. 16, no. 8, pp. 449466, 2005.

[90] P. Jeandet, R. Bessis, M. Sbaghi, and P. Meunier, "Production of the phytoalexin resveratrol by grapes as a response to botrytis attack under natural conditions," Journal of Phytopathology, vol. 143, pp. 135-139, 1995.

[91] A. M. Rimando, W. Kalt, J. B. Magee, J. Dewey, and J. R. Ballington, "Resveratrol, pterostilbene, and piceatannol in Vaccinium berries," Journal of Agricultural and Food Chemistry, vol. 52, no. 15, pp. 4713-4719, 2004.

[92] L. Frémont, "Minireview: biological effects of resveratrol," Life Sciences, vol. 66, no. 8, pp. 663-673, 2000.

[93] C. F. Rueda-Clausen, V. W. Dolinsky, J. S. Morton, S. D. Proctor, J. R. B. Dyck, and S. T. Davidge, "Hypoxia-induced intrauterine growth restriction increases the susceptibility of rats to high-fat diet-induced metabolic syndrome," Diabetes, vol. 60, no. 2, pp. 507-516, 2011.

[94] S. L. Bourque, V. W. Dolinsky, J. R. B. Dyck, and S. T. Davidge, "Maternal resveratrol treatment during pregnancy improves adverse fetal outcomes in a rat model of severe hypoxia," Placenta, vol. 33, no. 5, pp. 449-452, 2012.

[95] M. J. Cudmore, W. Ramma, M. Cai et al., "Resveratrol inhibits the release of soluble fms-like tyrosine kinase (sFlt1) from human placenta," American Journal of Obstetrics and Gynecology, vol. 206, no. 3, pp. 253.e10-253.e15, 2012.

[96] A. Bergmann, S. Ahmad, M. Cudmore et al., "Reduction of circulating soluble Flt-1 alleviates preeclampsia-like symptoms in a mouse model," Journal of Cellular and Molecular Medicine, vol. 14, no. 6, pp. 1857-1867, 2010.

[97] D. J. Boocock, G. E. S. Faust, K. R. Patel et al., "Phase I dose escalation pharmacokinetic study in healthy volunteers of resveratrol, a potential cancer chemopreventive agent," Cancer Epidemiology Biomarkers and Prevention, vol. 16, no. 6, pp. 1246-1252, 2007.

[98] J. Y. Jang, D. Park, S. Shin et al., "Antiteratogenic effect of resveratrol in mice exposed in utero to 2,3,7,8tetrachlorodibenzo-p-dioxin," European Journal of Pharmacology, vol. 591, no. 1-3, pp. 280-283, 2008.

[99] G. Jahnke, M. Marr, C. Myers, R. Wilson, G. Travlos, and C. Price, "Maternal and developmental toxicity evaluation of melatonin administered orally to pregnant Sprague-Dawley rats," Toxicological Sciences, vol. 50, no. 2, pp. 271-279, 1999.

[100] B. Poeggeler, S. Saarela, R. J. Reiter et al., "Melatonin-a highly potent endogenous radical scavenger and electron donor: new aspects of the oxidation chemistry of this indole accessed in vitro," Annals of the New York Academy of Sciences, vol. 738, pp. 419-420, 1994.

[101] R. J. Reiter, D. X. Tan, B. Poeggeler, A. Menendez-Pelaez, L. D. Chen, and S. Saarela, "Melatonin as a free radical scavenger: implications for aging and age-related diseases," Annals of the New York Academy of Sciences, vol. 719, pp. 1-12, 1994.

[102] R. J. Reiter, D. X. Tan, L. C. Manchester, and W. Qi, "Biochemical reactivity of melatonin with reactive oxygen and nitrogen species: a review of the evidence," Cell Biochemistry and Biophysics, vol. 34, no. 2, pp. 237-256, 2001.

[103] H. S. Mahal, H. S. Sharma, and T. Mukherjee, "Antioxidant properties of melatonin: a pulse radiolysis study," Free Radical Biology and Medicine, vol. 26, no. 5-6, pp. 557-565, 1999.

[104] D. X. Tan, L. C. Manchester, R. J. Reiter et al., "Melatonin directly scavenges hydrogen peroxide: a potentially new metabolic pathway of melatonin biotransformation," Free
Radical Biology and Medicine, vol. 29, no. 11, pp. 1177-1185, 2000.

[105] H. G. Richter, J. A. Hansell, S. Raut, and D. A. Giussani, "Melatonin improves placental efficiency and birth weight and increases the placental expression of antioxidant enzymes in undernourished pregnancy," Journal of Pineal Research, vol. 46, no. 4, pp. 357-364, 2009.

[106] A. S. Thakor, E. A. Herrera, M. Serón-Ferré, and D. A. Giussani, "Melatonin and vitamin C increase umbilical blood flow via nitric oxide-dependent mechanisms," Journal of Pineal Research, vol. 49, no. 4, pp. 399-406, 2010.

[107] C. O. Lemley, A. M. Meyer, L. E. Camacho et al., "Melatonin supplementation alters uteroplacental hemodynamics and fetal development in an ovine model of intrauterine growth restriction," American Journal of Physiology, vol. 302, no. 4, pp. R454-R467, 2012.

[108] J. Eng, W. A. Kleinman, L. Singh, G. Singh, and J. P. Raufman, "Isolation and characterization of exendin-4, an exendin3 analogue, from Heloderma suspectum venom. Further evidence for an exendin receptor on dispersed acini from guinea pig pancreas," The Journal of Biological Chemistry, vol. 267, no. 11, pp. 7402-7405, 1992.

[109] Y. H. Chen, D. X. Xu, J. P. Wang et al., "Melatonin protects against lipopolysaccharide-induced intra-uterine fetal death and growth retardation in mice," Journal of Pineal Research, vol. 40, no. 1, pp. 40-47, 2006.

[110] D. J. Drucker and M. A. Nauck, "The incretin system: glucagon-like peptide-1 receptor agonists and dipeptidyl peptidase- 4 inhibitors in type 2 diabetes," The Lancet, vol. 368, no. 9548, pp. 1696-1705, 2006.

[111] M. A. Nauck, N. Kleine, C. Orskov, J. J. Holst, B. Willms, and W. Creutzfeldt, "Normalization of fasting hyperglycaemia by exogenous glucagon-like peptide 1(7-36)amide in type 2 (non-insulin-dependent) diabetic patients," Digestion, vol. 36, pp. 741-744, 1993.

[112] M. A. Nauck, U. Niedereichholz, R. Ettler et al., "Glucagonlike peptide 1 inhibition of gastric emptying outweighs its insulinotropic effects in healthy humans," American Journal of Physiology, vol. 273, no. 5, pp. E981-E988, 1997.

[113] D. J. Drucker, “The biology of incretin hormones," Cell Metabolism, vol. 3, no. 3, pp. 153-165, 2006.

[114] D. E. Moller, "New drug targets for type 2 diabetes and the metabolic syndrome," Nature, vol. 414, no. 6865, pp. 821827, 2001.

[115] A. A. Young, B. R. Gedulin, S. Bhavsar et al., "Glucoselowering and insulin-sensitizing actions of exendin-4: studies in obese diabetic (ob/ob, db/db) mice, diabetic fatty Zucker rats, and diabetic rhesus monkeys (Macaca mulatta)," Diabetes, vol. 48, no. 5, pp. 1026-1034, 1999.

[116] D. G. Parkes, R. Pittner, C. Jodka, P. Smith, and A. Young, "Insulinotropic actions of exendin-4 and glucagonlike peptide-1 in vivo and in vitro," Metabolism, vol. 50, no. 5, pp. 583-589, 2001.

[117] R. Goke, H. C. Fehmann, T. Linn et al., "Exendin-4 is a high potency agonist and truncated exendin-(9-39)amide an antagonist at the glucagon-like peptide 1-(7-36)amide receptor of insulin- secreting $\beta$-cells," The Journal of Biological Chemistry, vol. 268, no. 26, pp. 19650-19655, 1993.

[118] G. Xu, D. A. Stoffers, J. F. Habener, and S. Bonner-Weir, "Exendin- 4 stimulates both $\beta$-cell replication and neogenesis, resulting in increased $\beta$-cell mass and improved glucose tolerance in diabetic rats," Diabetes, vol. 48 , no. 12, pp. 2270 2276, 1999. 
[119] R. A. DeFronzo, R. E. Ratner, J. Han, D. D. Kim, M. S. Fineman, and A. D. Baron, "Effects of exenatide (exendin-4) on glycemic control and weight over 30 weeks in metformintreated patients with type 2," Diabetes Care, vol. 28, no. 5, pp. 1092-1100, 2005.

[120] O. G. Kolterman, J. B. Buse, M. S. Fineman et al., "Synthetic exendin-4 (exenatide) significantly reduces postprandial and fasting plasma glucose in subjects with type 2 diabetes," The Journal of Clinical Endocrinology and Metabolism, vol. 88, no. 7, pp. 3082-3089, 2003.

[121] R. A. Simmons, L. J. Templeton, and S. J. Gertz, "Intrauterine growth retardation leads to the development of type 2 diabetes in the rat," Diabetes, vol. 50, no. 10, pp. 2279-2286, 2001.

[122] D. A. Stoffers, B. M. Desai, D. D. DeLeon, and R. A. Simmons, "Neonatal exendin-4 prevents the development of diabetes in the intrauterine growth retarded rat," Diabetes, vol. 52, no. 3, pp. 734-740, 2003.

[123] S. E. Pinney, L. J. Jaeckle Santos, Y. Han, D. A. Stoffers, and R. A. Simmons, "Exendin-4 increases histone acetylase activity and reverses epigenetic modifications that silence Pdx1 in the intrauterine growth retarded rat," Diabetologia, vol. 54, pp. 2606-2614, 2011.

[124] J. N. Ham, M. F. Crutchlow, B. M. Desai, R. A. Simmons, and D. A. Stoffers, "Exendin-4 normalizes islet vascularity in intrauterine growth restricted rats: potential role of VEGF," Pediatric Research, vol. 66, no. 1, pp. 42-46, 2009.

[125] J. M. Lehmann, L. B. Moore, T. A. Smith-Oliver, W. O. Wilkison, T. M. Willson, and S. A. Kliewer, "An antidiabetic thiazolidinedione is a high affinity ligand for peroxisome proliferator-activated receptor $\gamma(\operatorname{PPAR} \gamma)$," The Journal of Biological Chemistry, vol. 270, no. 22, pp. 12953-12956, 1995.

[126] M. Garg, M. Thamotharan, G. Pan, P. W. N. Lee, and S. U. Devaskar, "Early exposure of the pregestational intrauterine and postnatal growth-restricted female offspring to a peroxisome proliferator-activated receptor- $\gamma$ agonist," American Journal of Physiology, vol. 298, no. 3, pp. E489-E498, 2010.

[127] T. Vo, G. Sohi, A. Revesz, and D. B. Hardy, "Maternal protein restriction results in altered transcriptional and epigenetic regulation of hepatic liver $\mathrm{X}$ receptor (LXR) target genes leading to impaired glucose homeostasis in adult rat offspring," Reproductive Sciences, vol. 19, article 118A, 2012.

[128] N. Mitro, P. A. Mak, L. Vargas et al., "The nuclear receptor LXR is a glucose sensor," Nature, vol. 445, no. 7124, pp. 219223, 2007.

[129] J. J. Repa and D. J. Mangelsdorf, "The role of orphan nuclear receptors in the regulation of cholesterol homeostasis," Annual Review of Cell and Developmental Biology, vol. 16, pp. 459-481, 2000.

[130] J. R. Schultz, H. Tu, A. Luk et al., "Role of LXRs in control of lipogenesis," Genes and Development, vol. 14, no. 22, pp. 2831-2838, 2000.

[131] B. A. Laffitte, L. C. Chao, J. Li et al., "Activation of liver $\mathrm{X}$ receptor improves glucose tolerance through coordinate regulation of glucose metabolism in liver and adipose tissue," Proceedings of the National Academy of Sciences of the United States of America, vol. 100, no. 9, pp. 5419-5424, 2003.

[132] G. Sohi, A. Revesz, E. Arany, and D. B. Hardy, "The liver $\mathrm{X}$ receptor mediates the impaired cholesterol metabolism exhibited in the offspring of maternal protein restricted rats," Reproductive Sciences, vol. 18, article F163, 2011. 


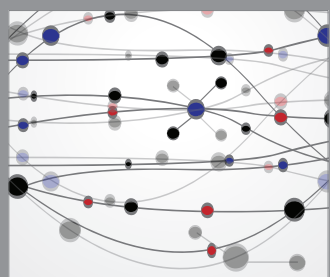

The Scientific World Journal
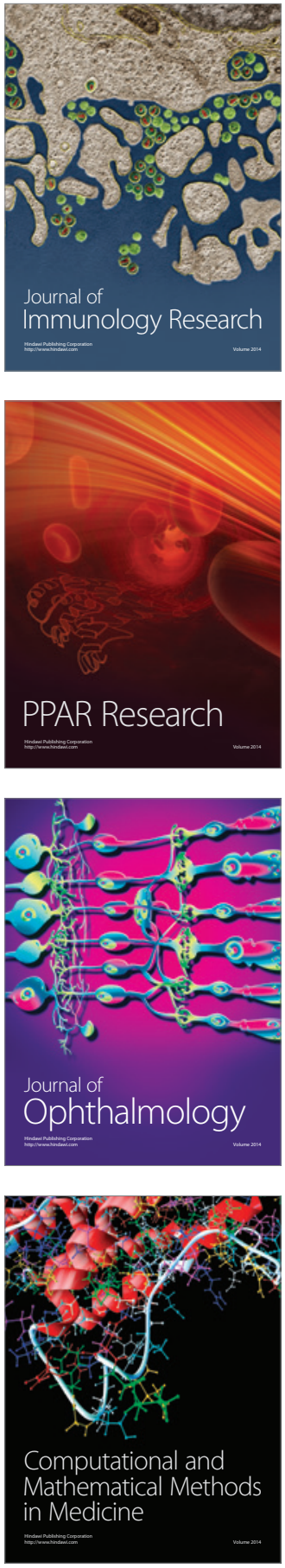

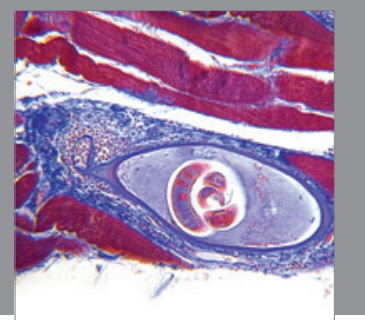

Gastroenterology

Research and Practice
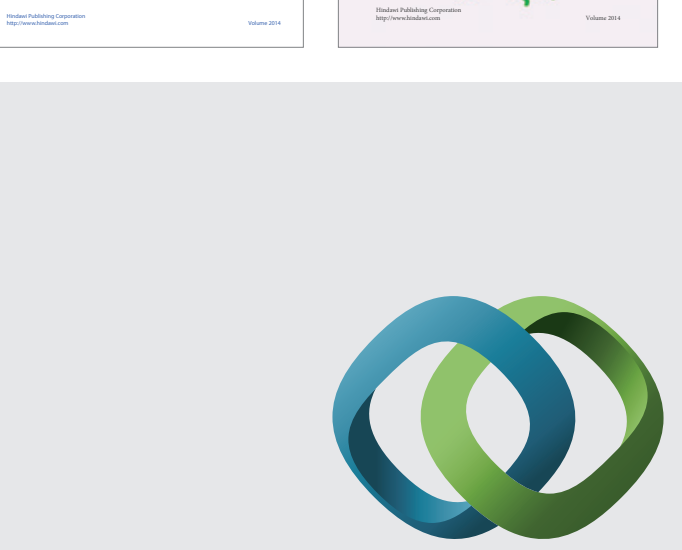

\section{Hindawi}

Submit your manuscripts at

http://www.hindawi.com
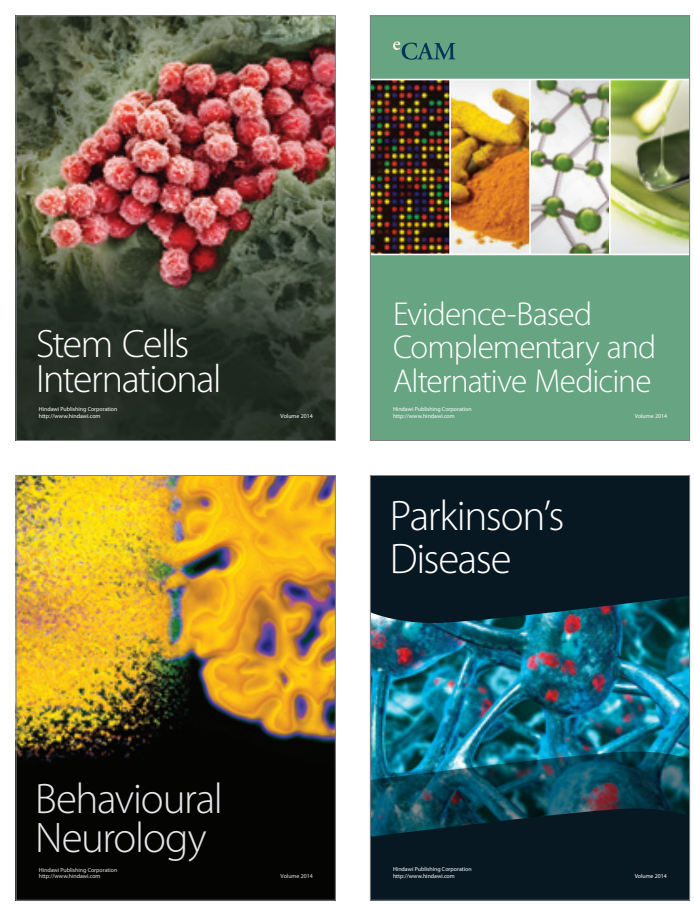

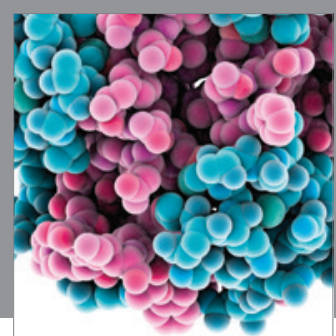

Journal of
Diabetes Research

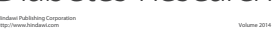

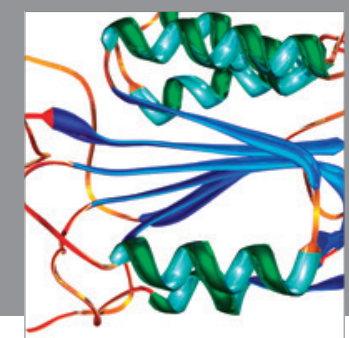

Disease Markers
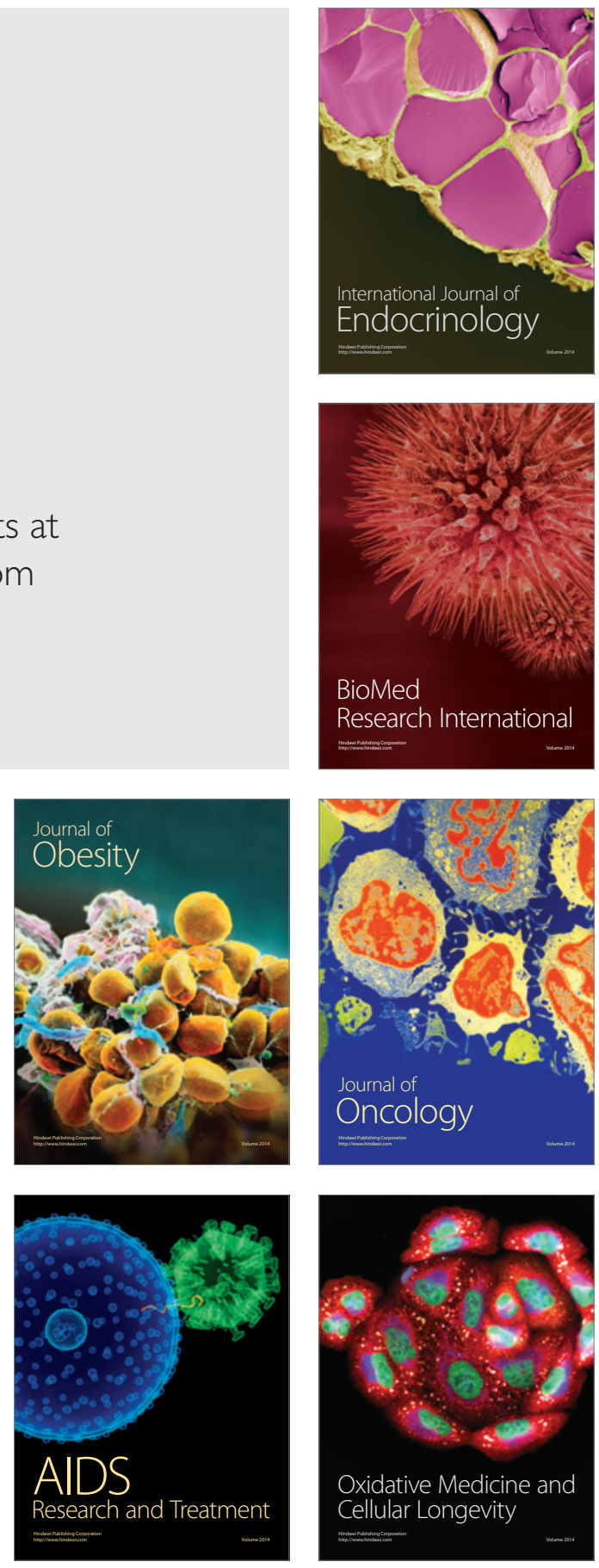